\section{AB0840 LOCAL FRACTURE LIAISON SERVICE (FLS): CHARACTERISTICS AND FIRST 6 MONTHS OF EVOLUTION IN PATIENTS AFTER HIP FRACTURE: PRELIMINARY RESULTS}

J. Rosas ${ }^{1}$, C. Cano ${ }^{1}$, M. Lorente ${ }^{1}$, A. Pons ${ }^{1}$, E. Salas ${ }^{1}$, T. Llinares ${ }^{2}$ M. Hernández ${ }^{3}$, J.M. Senabre-Gallego ${ }^{1}$, M. Marco-Mingot ${ }^{4}$, J.D. Alvarado ${ }^{3}$ G. Santos-Soler ${ }^{1}$, H. Arcos ${ }^{3}$, A. García ${ }^{3}$, J.I. Hernández ${ }^{3}$, J.J. Jiménez ${ }^{3}$, X. Barber ${ }^{5}$, C. López ${ }^{3}$, M.D. López ${ }^{3}$, A.M. Molinos ${ }^{3}$, B. Statti ${ }^{3}$,

M. Sanchís-Selfa ${ }^{5}$ on behalf of FLS-HMB and AIRE-MB Groups. ${ }^{1}$ Rheumatology Department; ${ }^{2}$ Traumatology Department; ${ }^{3}$ Radiology Derpartment; ${ }^{4}$ Laboratory Department, Hospital Marina Baixa, Villajoyosa (Alicante); ${ }^{5} \mathrm{ClO}$, Universidad Miguel Hernández, Elche, Spain

Background: Hip fracture has great impact on morbi-mortality, but a large percentage of patients do not receive treatment.

Objectives: To know the characteristics of patients whith hip fracture and its evolution in the first 6 months.

Methods: A prospective, 6-month follow-up study of patients over 60 years old admitted for hip fracture, evaluated in a local FLS. At 3 months after discharge, patients are evaluated for: epidemiological data, fracture income (days of admission, prior and discharge of osteoporosis (OP) drugs, general biochemistry and vitamin D), OP records and possible diseases or osteopenizing drugs, lumbar spine and hip Bone densitometry (BMD) lateral dorsal and lumbar spine radiology and the treatment was decided. The electronic history before and after 6 months of the fracture were reviewed.

Results: Of 152 patients $>60$ years old, admitted in 2016 due hip fracture, 77 $(51 \%)$ were during the first 6 months. However, radiology or BMD data were not available for $30(39 \%)$ patients, $16(21 \%)$ for death and $14(18 \%)$ for loss of followup. Mean BMI was $26.02 \pm 6$.2. The mean age of menopause was $49 \pm 5$ years. $1 \%$ of the patients received corticosteroids and $2 \%$ of patients an osteopenizing disease (COPD) was found. Mean time of admission was $7.57 \pm 2.51$ days. In $3 \%$ of the patients, before the fracture were receiving OP treatment, which continued to discharge. The mean level of calcium, phosphorus and alkaline phosphatase was normal. However, the mean level of $25 \mathrm{OH}$ vitamin D was $13.55 \pm 8.63 \mathrm{ng} / \mathrm{ml}$ (median: $12 \mathrm{ng} / \mathrm{ml}$, range: $<4$ to $29 \mathrm{ng} / \mathrm{ml}$ ).

In 11 of the $27(41 \%)$ patients, in whom radiology was available, the presence of vertebral fracture was demonstrated. The mean T-score for lumbar BMD was $1.8 \pm 1.65 \mathrm{DE}$ (32\%: the result was normal, $36 \%$ osteopenia, $32 \%$ OP), femoral neck $2.59 \pm 0.77 \mathrm{DE}(27 \%$ : osteopenia, $77 \%$ OP) and in total hip: $2.56 \pm 0.86 \mathrm{DE}$ (56\%:osteopenia and $44 \%$ OPand In Ward of 3.2 DE. $100 \%$ of patients evaluated in Rheumatology, initiated treatment for OP: zoledronate: $40 \%$, alendronate: $20 \%$, denosumab: $25 \%$, PTH: $15 \%$.

Conclusions: In patients with hip fracture: 1) Mortality is high (21\%), in the first 6 months after fracture. 2) The prevalence of vertebral fracture is $40 \%$. 3) It is accompanied by very low blood levels of vitamin D. 4) In a high percentage the result of BMD is normal or osteopenia. 5) A minimum number of patients receive specific treatment for osteoporosis after fracture. 6) Evaluation in a FLS, ensures the evaluation and treatment of patients.

Acknowledgements: The study was supported by a research grant from the Asociación para la Investigación en Reumatología de la Marina Baixa (AIREMB).

Disclosure of Interest: None declared

DOI: 10.1136/annrheumdis-2017-eular.4234

\section{AB0841 MEDICAL AND SOCIAL CONSEQUENCES IN HIP FRACTURES} DEPENDING ON THE METHOD OF TREATMENT

\section{J.V. Averkieva, T. Raskina. State Medical University Kemerovo, Kemerovo,} Russian Federation

Background: medical and social significance of osteoporosis is determined by its consequences - fractures of the vertebrae and the bones of the peripheral skeleton leading to high rates of mortality and disability among older adults. Purpose: to follow basic health and social consequences among the surviving patients with hip fractures aged 50 years or older at 6, 24 months.

Objectives: The study included 432 patients (328 women and 104 men) with radiographic evidence of hip fractures that occurred with minimal trauma.

Methods: Surgical treatment was performed in 171 (40,04\%) patients, conservative treatment-261(59.96\%).

Results: tracked mortality in hip fractures in 432 patients. It was found that in the first 6 months in the surgical treatment of deaths registered in $11(6,43 \%)$ patients and in $84(32.18 \%)$ - the conservative $(\mathrm{p}<0.0001)$. After 12 months after fracture increased mortality rate after the surgical treatment and after conservative $(12.9 \%$ and $44.81 \%$, respectively, $p<0.0001$ ). It was revealed that in the first 6 months in patients with surgical treatments bedridden were $10(8.0 \%)$ men and 78 - a group with conservative treatment $(66.67 \%)(p<0.0001)$

Restriction of physical activity within the room was observed in $86(68.8 \%)$ patients with surgery, and in $30(25.64 \%)$ patients - with conservative treatment $(p<0.0001)$. Aids used after surgical treatment of $105(84.0 \%)$ patients after conservative - $34(29.0 \%)(p<0.0001)$. Social impact showed that after 6 months of observation revealed a low proportion of patients with complete recovery of function after a surgery, or after conservative treatment $(8.0 \%$ and $5.13 \%$, respectively; $p=0.5)$. After 24 months from the time of the fracture using surgical methods bedridden stayed only $1(0.4 \%)$ and 16 patients $(13.68 \%)$ - with conservative methods $\left(\chi^{2}=18,3 ; p<0.0001\right)$. There was a significant decrease in the number of patients with limited motion activity within the room in the group with surgery and in the group with conservative $(10.4 \%$ and $26.5 \%$, respectively, $\mathrm{p}=0.002$ ). When surgical treatment aids continued to use $38.4 \%$ (48 patients) under conservative treatment $-58.97 \%$ (69 people) $\left(\chi^{2}=10,24 ; p=0.002\right)$. Full restoration of function was observed in $72(57.6 \%)$ and $32(27.35 \%)$ patients who received surgical and conservative treatment, respectively $\left(x^{2}=4,62 ; p<0.0001\right)$ Conclusions: the obtained during this study data suggest that the immediate and long-term consequences in patients with a fracture of the proximal femur depends on the method of treatment. Surgical treatment is the method of choice for the treatment of patients with this type of fracture.

Disclosure of Interest: None declared

DOI: 10.1136/annrheumdis-2017-eular.5716

\section{AB0842 SARCOPENIA AND OSTEOPOROSIS IN PATIENTS WITH RHEUMATOID ARTHRITIS}

K. Aminov. Medical Radiology, Tashknet Institute for Postgraduate Medical Education, Tashkent, Uzbekistan

Background: Musculoskeletal disorders in RA are characterized by lesions of the peripheral joints, the development of local and systemic osteoporosis (OP), as well as a decrease in muscle mass and strength, which are currently being considered within the framework associated with chronic diseases syndrome sarcopenia and cachexia.

Objectives: To determine the prevalence and the relationship between sarcopenia and $O P$ in patients with RA.

Methods: 156 RA patients were examined, of whom 83 postmenopausal women (mean age-61.7 years) and 73 males (mean age, 59 years). The control group consisted of 35 healthy subjects matched for age and sex. Exclusion criteria were: other rheumatic and endocrine diseases, severe somatic diseases, cancers, etc. The states of bone mineral density (BMD) at the lumbar spine (L1-L4) and femoral bone were assessed by dual-energy X-ray absorptiometry (DXA).

Results: Most RA patients ( $83 \%$ women and $63 \%$ men) were observed to decrease in BMD of osteopenia/OP level. BMD were negatively correlated with radiographic stage of RA, the DAS 28 and HAQ. IPC also revealed significant correlations with laboratory parameters such as creatinine, total protein, albumin, rheumatoid factor, and 1,25 $(\mathrm{OH}) \mathrm{D}$. Investigation of body composition showed a statistically significant reduction ITM RA patients compared to the control group, with no differences between the groups for fat mass. Sarcopenia had $25 \%$ of women and $55 \%$ men with RA, whereas the control groups, $8.7 \%$ and $0 \%$, respectively. The majority of patients of both sexes sarcopenia observed on the background of the normal range of body fat index. Status of TM in patients with RA was statistically significant $(p<0,05)$ associated with femoral BMD and lumbar spine $(r=0,3)$, BMI $(r=0,5)$, force brush compression $(r=0,4)$ RA radiographic stage $(r=-0,4)$, indicators of total protein $(r=0,5)$.

Conclusions: Patients with RA, together with OP/osteopenia have a significant reduction in muscle (lean) mass. Sarcopenia in patients with RA was observed in the majority of men ( $55 \%$ ) and $25 \%$ of women, significantly more than the control groups. Implementation of the DRA with the program "whole body" will allow time to identify not only bone, but also muscle loss in RA patients, which will help to intensify targeted therapy.

Disclosure of Interest: None declared

DOI: 10.1136/annrheumdis-2017-eular.3165

\section{AB0843 RELATIONSHIP BETWEEN THE HISTOLOGICAL CLASSIFICATION OF MARSH AND THE AFFECTATION OF THE BONE METABOLISM IN PATIENTS WITH A RECENT DIAGNOSIS OF CELIAC DISEASE}

L. López ${ }^{1}$, M. Larrea ${ }^{2}$, A. Erra ${ }^{1} .{ }^{1}$ Rheumatology; ${ }^{2}$ Gastroenterology, Hospital San Rafael, Barcelona, Spain

Background: Celiac disease is a chronic autoimmune pathology that affects people with genetic predisposition, caused by a permanent intolerance to gluten. Its prevalence has been estimated at around $1 \%$ but about $30 \%$ of patients are diagnosed after age 60. Its diagnosis is made through clinical data, serological markers, study of duodenal biopsy (BD) and response to the gluten-free diet. The histological study (Marsh classification) remains the gold standard to the diagnosis and allows classification of the disease in 4 types: grade I (less histological lesion) to grade IV (total duodenal mucosal atrophy).In these patients the deficiency of $25-\mathrm{OH}$ vitamin $\mathrm{D}$ (vit $\mathrm{D}$ ) is very frequent and is one of the causes of osteomalacia associated with malabsorption.

Objectives: To evaluate if there is a relation between the histological classification of Marsh and the bone metabolism in patients with a recent diagnosis of celiac disease.

Methods: Prospective study, which included all patients with a recent diagnosis of celiac disease by the Digestive Service during the period 2014-2016. This diagnosis was made through a clinical, serological (anti-transglutaminase IgA, anti-endomysium $\lg A$ ), histological BD and genetic study (HLA DQ2 and HLA DQ8)

All patients underwent a study of phospho-calcium metabolism including: calcemia, phosphataemia, vit D, PTH, alkaline phosphatases, 24-hour calciuria and a densitometric study (BMD). We present the inclusion data of these patients 